\title{
Computational Fluid Dynamics Modeling in Respiratory Airways Obstruction: Current Applications and Prospects
}

\author{
Oyejide James Ayodele*, Atoyebi Ebenezer Oluwatosin, Olutosoye Christian Taiwo, \\ Ademola Adebukola Dare
}

Department of Biomedical Engineering, University of Ibadan, Ibadan, Nigeria

Email address:

ayoyja@outlook.com (O. J. Ayodele)

${ }^{*}$ Corresponding author

\section{To cite this article:}

Oyejide James Ayodele, Atoyebi Ebenezer Oluwatosin, Olutosoye Christian Taiwo, Ademola Adebukola Dare. Computational Fluid Dynamics Modeling in Respiratory Airways Obstruction: Current Applications and Prospects. International Journal of Biomedical Science and Engineering. Vol. 9, No. 2, 2021, pp. 16-26. doi: 10.11648/j.ijbse.20210902.12

Received: April 15, 2021; Accepted: May 3, 2021; Published: May 15, 2021

\begin{abstract}
Breathing conditions pertaining to nasal obstruction, obstructive sleep apnea, and airflow resistance in the human lower airways have been investigated extensively by researchers over the years. Due to the availability of advanced computer numerical models, such as computational fluid dynamics (CFD), researchers have made progressive studies of airflow characteristic, especially the effects of airflow pressure, velocity and wall shear stress in human obstructive airways. Studies utilizing CFD have enhanced clinical understanding of the physiology and pathophysiology of the respiratory system through the concept of three-dimensional models that facilitate airflow simulation. The main objective of this article is to review recent CFD literature on nasal airflow and lower airway obstruction. The review covers the role of segmentation threshold in the outcome of airflow simulation in the nasal cavity, and results of fluid structure interaction (FSI) and computational fluid dynamics in nasal obstruction and airway collapse in obstructive sleep apnea were also correlated. For models of the lower airways, we evaluated the effect of extra-thoracic airway (ETA) on downstream airflow during simulation against the popular Weibel's model. In the concluding section, we discussed the advantages, limitations, and prospects (precisely with deep machine learning) of computational fluid dynamics in the clinical assessment and investigation of respiratory diseases.
\end{abstract}

Keywords: Computational Fluid Dynamics (CFD), Fluid-structure Interaction (FSI), Airway Obstruction, Segmentation Threshold (ST), Obstructive Sleep Apnea (OSA)

\section{Introduction}

Computational fluid dynamics (CFD) emerged during the last five decades, making it a relatively young discipline [1]. For more than two decades, the virtual reality software that allows users to manipulate flow data to investigate and validate fluid properties has remained indisputably one of the interesting tools in the area of fluid mechanics. As one of the branches of fluid mechanics, it employs numerical methods and algorithmic processes to solve and evaluate problems involving fluid flows [2]. CFD technique is a proven powerful and cost effective tool relevant in the study of complex flow patterns. It possesses the capability of giving detailed information in physical models that aid prediction of airflow behavior in real-life scenarios [3-5]. Due to its versatility, the application of CFD has gained wide range of use in many engineering fields such as; Biological Engineering [6], Environmental Engineering [7], and has been established as relevant tool in the field of Medicine [8].

\subsection{CFD in Respiratory Disease}

The today society is characterized by highly developed industries and technologies that are contributing immensely to a stress-free life, but not without their health implications in cases where aerosols (smokes, particles, etc.) are not properly managed. Consequently, millions of people across the globe suffer from lung diseases like bronchitis and chronic obstructive pulmonary disease (COPD) resulting from limitation of airflow into the lungs [9]. According to World Health Organization, chronic obstructive pulmonary 
disease has increased rapidly worldwide as the fourth major causes of death and will increase to the third in 2030 [10]. Respiratory diseases require medical attention at an early stage, which is often preceded by a medical diagnosis. Early diagnostic approaches typically involve probing the human body in order to trigger a reaction for the investigation of airflow resistance $[11,12]$. These approaches detect impairment in the airway through the use of Force Oscillation Technique (FOT) [13], the pneumotachograph technique [14] and dynamic spirometry [15]. However, the above-mentioned techniques of assessing respiratory disorders have limitations which are discussed by Joe et al. [16-21]. Therefore, recent studies have taken advantage of advanced scientific computations such as CFD, which closely mimic the human airways to deduce airflow behavior in the human respiratory system.

Due to medical ethics and other complexities involved, direct assessment and collection of experimental data in major human respiratory regions is impossible [22]. For example, in the bronchial tree and other delicate structures, direct airflow simulation in human bifurcating airways cannot be easily made. As such, anatomic experiments as well as advanced medical imaging (magnetic resonance imaging and computed tomography) have become handy in extracting such data from biological systems [23]. With the aid of CFD software, the extracted data such as the length, diameter, and thickness of the airway (for instance, the bronchi or nasal cavity) can be used as geometry guide to reconstruct the airway anatomy and perform simulations that reveal substantial information about the airflow field [24].

Not until recent times, the application of CFD in the studies of human airways was not a common practice. Researchers began firstly by modeling patterns of airflow in the lungs, and evaluating pressure, temperature, and shear stress on the respiratory tract [25]. Thereafter, researchers looked into the study of common aberrations such as septal deviation, septal perforations and inferior turbinate hypertrophy [26, 27]. Recently, CFD has been used to model and predict the effects of surgery and therapeutic interventions [28]. The applications evaluated in this review focuses on 3-dimensional CFD analyses of obstructed upper and lower airways of the respiratory system. The application of CFD in this subject area is promising because it has intensified the clinical understanding of pathophysiology of the respiratory system.

\subsection{Airway Obstruction}

The respiratory airways all work like a system of pipe through which air is funneled down into the lungs, beginning with the nasal and oral cavity in the upper respiratory system through the trachea to the bronchi and bronchioles in the lower extremities [29]. This airflow channel, under physiologic conditions, is kept open for ease of air passage at all times. However, the airways are prone to obstruction, which often leads to partial or total airflow blockage [30]. Furthermore, during human growth and development from infancy to adulthood, dramatic changes occur in the respiratory system that may mediate pathologic processes leading to airway obstruction [31]. Obstruction in the human airways, whether chronic or acute, definitely has considerable overall effects on the respiratory system as a whole [32]. Hence, early and accurate assessment of airflow limitation in patients with obstructive airway symptoms is vital.

\section{Upper Airway Obstruction}

The upper airway consists of the nasal cavities and passages, paranasal sinuses, pharynx and the upper part of the vocal cords. Figure 1 refers to the description of the major parts of the upper airway. Any hindrance to free flow in any of this region is referred to as upper airway obstruction. Such hindrance can be pathologic and/or anatomic and may vary depending on the site of obstruction and the nature of obstruction, be it acute or chronic [33]. Examples of common symptoms include; nasal blockage, sleep apnea and snoring. CFD has been employed by researchers, over the years, alongside accurate health history, radiological investigations and respiratory assessment to examine the effects of upper airway blockage [34, 35]. The research outcomes have helped to improve respiratory conditions of patients pre-operation and post-surgery. This is aided by CFD capabilities to handle quantitative assessment of transport phenomena in the upper airway which includes heat exchange, moisture transport, odorant uptake in the olfactory cleft, and regional delivery of pharmaceutical aerosols [36].

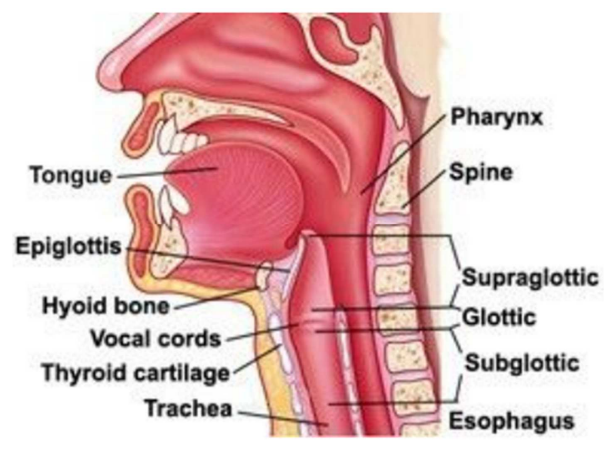

Figure 1. Description of the upper airway.

Unlike other methods of evaluating nasal airflow such as rhinomanometry, CFD offers highly graphical model with great level of precision to gain better understanding of the nature of nasal airflow [37]. The first step when analyzing upper airway obstruction using CFD is to reconstruct the anatomical geometry model using data derived from scanned images (MRI or CT) of the upper airway of a patient. The image is then exported into commercial software such as MIMICS, where the grey scale image is treated into binary image by setting segmentation threshold value based on the pixel intensity of the original image. This is done after the fluid domain of interest has been identified, allowing the user to partition the digital image into multiple segments such as airspace, bone, soft platelet etc. [38, 39].

In vivo observations or in vitro experiments were some of 
the early processes employed in determining human upper airway flow patterns [40-44]. Although, these processes offered profound descriptions of airflow patterns in the airway passages of different subjects, quantitative data describing distribution of airflow was limited. This is due to the challenges involved and the huge cost of administering in-vivo observations and in-vitro experiments [45, 46]. Most of these reported studies simulated the airflow field in the unilateral nasal cavity or part of the respiratory tract [47-52]. However, comparative research providing detailed evidence about transient airflow in the whole upper airway was limited [45]. The limitation is obviously due to anatomical complexities of detailed geometry assessments of airflow patterns in the upper airway; thus, the airway geometry from oral cavity to intra-thoracic have gained much attention in most of the previous relevant researches without considering the nasal cavity [46-50].

Fortunately, models of the nasal cavity anatomical geometry is currently possible with computed tomographic scan data, paving way for researches with promising precision and accuracy. Consequently, researchers have compared the airflow field physiognomies of the upper airways which included the oropharynx, oral and nasal cavity, and soft palate movement between healthy human subjects (controls) and subjects with airflow resistance, such as obstructive sleep apnea (OSA) syndrome. For instance, Endalew [30] evaluated the effect of airway geometry on internal pressure and flow resistance in a pharyngeal airway model of three children with OSA syndrome and three normal controls. He concluded that the flow at resting peak inhalation/exhalation appears to be at steady state [51- 53]. However, Xu et al. [54] employed 3dimensional CFD models of the same pharyngeal airway, including the nasal cavity, to examine the airflow behavior in an adult OSA patient and observed that the airflow behavior in the pharyngeal airway of subjects with OSA syndrome is made up of a turbulent jet, which is formed by area restriction at the velopharynx. Invariably, the difference in anatomical geometry in the model influenced CFD results in the OSA patients.

Furthermore, Jin et al. [45] presented a model of the upper airway that consists of the nasal cavity, pharynx, larynx and trachea. The model includes triple bifurcation showing generations G0 to G3 in symmetry. The geometry of the nasal cavity-trachea was recreated from images obtained from CT scan of a 30-year old male volunteer who had no history of respiratory issues. Figure 2 refers to the description of the coronal section from the nostril to pharynx.

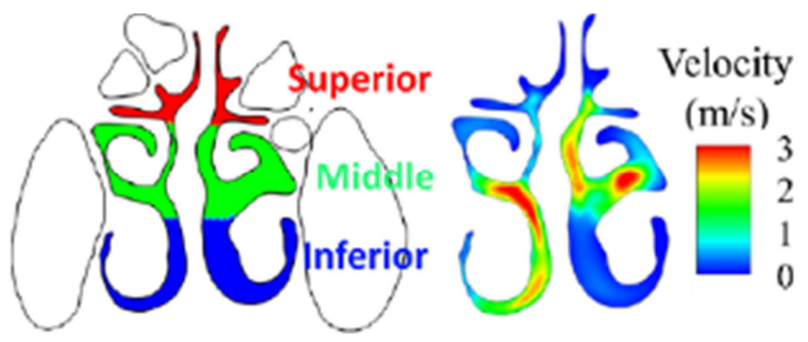

Figure 2. Definition of the regions of inferior, middle, and superior airway in a $3 D F E$ model of the upper airway from the nostril to the pharynx.
By assessing the turbulence model, Jin et al. [45] reported that deformations induced by airflow mostly influence the abnormal airway collapse experienced (Figure 3). Thus, opining that the analysis of anatomically accurate CFD replicas of the human airway employing computed tomographic data and Weibel's lung model, may pave way for better studies of airflow behavior in the airway from the nose to triple bifurcation. To investigate reported deformations imposed by airflow, such as in [45], researchers are currently employing the Fluid-Structure Interaction (FSI) which is discussed in the next heading.

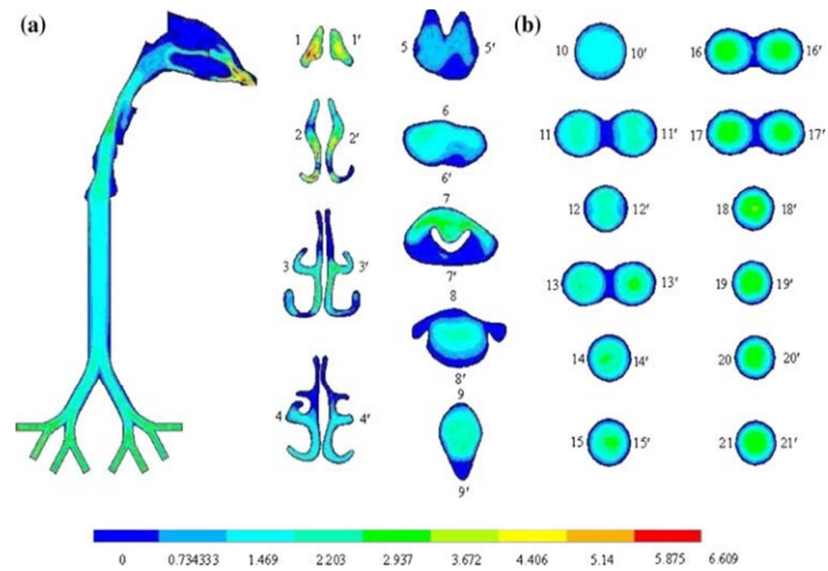

Figure 3. Flow rate distribution at the moment of maximum peak inspiratory in the model consisting of nasal cavity, pharynx, larynx and trachea, as well as a symmetric triple bifurcation representing Generations G0 to G3.

\subsection{Fluid Structure Interaction (FSI)}

When fluids flow across a pliable structure, the flow motion imposes pressure on the structure. In obstructive human airway, the obstruction leads to resistance which in most cases creates airflow pressure on the wall of the airway tract [55]. To save simulation time, cost and complexity, three dimensional models prepared for inspiratory simulation, especially in nasal cavity, typically isolate the airspace from deformable geometry that interacts with airflow [40]. However, studies that have been limited to relatively small deformations have often ignored quantifying airflow limitation in the deformed region [56-59]. Other studies like Pirnar et al. [60] that quantified coupling between airway structure and flow motion using FSI have reported a robust correlation with CFD analyses in nasal obstruction, and airway collapse in obstruction sleep apnea. Subramaniam et al. [61] also reported in their study that the results of FSI technique gave realistic analysis than CFD in both compliant and rigid models of the respiratory airways.

The only limitation in the application of FSI in most studies is that they lack experimental validation of the methodology. Trung et al. [62] considered validating their numerical results with experiments. Precisely, they developed a collapsible three-dimensional FSI models to investigate an abnormal upper airway collapse especially the prediction that the upstream pressure profile becomes independent' of downstream pressure after flow limitation 
starts as given by Chang et al. [63]. They fabricated a physical replica of the human upper airway (scale of 1:1) using a combination of $3 \mathrm{D}$ printing and silicone mold that included the nasal cavity, pharynx, larynx, and trachea, evaluated as a classical starling resistor. Graphs plotted from the flow meter shows that the pressure-flow curve generated by the FSI simulations was independent of the breathing profile. This is validated by previous numerical research reports that suggested that pharyngeal compliance in obstructive sleep apnea patients may be estimated from peak flow measurements during sleep [64, 65]. FSI technique is currently an appreciated tool in correlating clinical assessments of airflow pattern in airway obstruction. The differences in the reported airflow patterns in CFD and FSI simulations depend on the parameters used in the modeling, such as complete or isolated geometry, and the pressure generated in the obstructive airway [64].

\subsection{Segmentation Threshold}

One other area of concern in modeling and simulation of airflow and particle deposition in the human nasal cavity is segmentation threshold. Segmentation is a useful tool in upper airways and airway tree, especially in situations with low resolution $\mathrm{CT}$ images used in airspace modeling and simulation [66-68]. The important reasons for segmentation threshold in CFD are for better comparison of nasal obstruction simulation results, and to isolate airspace region from other structures of the CT image. This approach saves time and cost and it is advisable that researchers report the segmentation threshold used to reconstruct the nasal anatomy during modeling [69].

Most studies involving segmentation have often considered the lower threshold limit set to a standard of $1000 \mathrm{HU}$ or similar value, depending on the software specification [70, 71]. There is currently no absolute threshold range for the upper limit and researches like Reynisson et al. [72] and Nakano et al. [73] who have worked at close but different ranges agree that what upper threshold range is best for upper airway simulation is open for debate. From their different studies, they realized that the optimal threshold for airway segmentation may vary for different CT scanners, CT protocols, airway regions, and patient-specific anatomy. The nasal cavity is known to be the most challenging part of the upper airway to be segmented [74]. Therefore, most studies of the nasal airway do not report the threshold for segmentation of their works [36]. To this end, Leong et al. [36] quantified how uncertainty in the segmentation threshold impacts CFD simulations of transport phenomena in the human nasal cavity. In this study, the subjects were three patients with nasal airway obstruction. The authors reconstructed the nasal airspace from the nostrils to nasopharynx, excluding all paranasal sinuses using three different threshold ranges of $800 \mathrm{HU},-550 \mathrm{HU}$ and $-300 \mathrm{HU}$ for the upper limits and a constant range of $-1,024$ for the lower limits as shown in figures 4 and 5, respectively. Distinctive information about the segmentation proved relevant in two ways: first, the cross-sectional area of the airspace in all patients increased systematically throughout the nasal cavity as the segmentation threshold was increased from the least to the highest range.

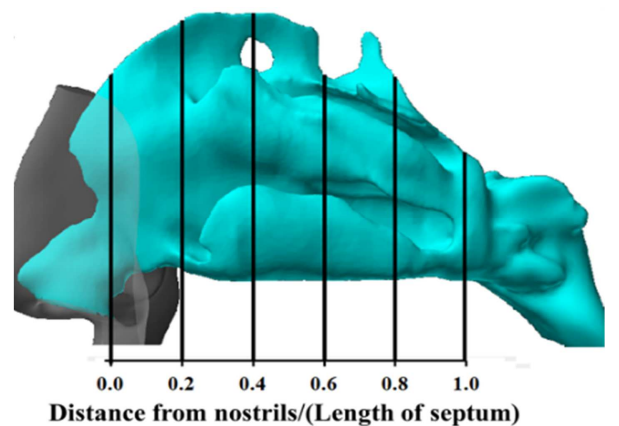

Figure 4. 3D description of distance from nostrils used to define the segmentation threshold in all three patients after pre-surgical CT scan.

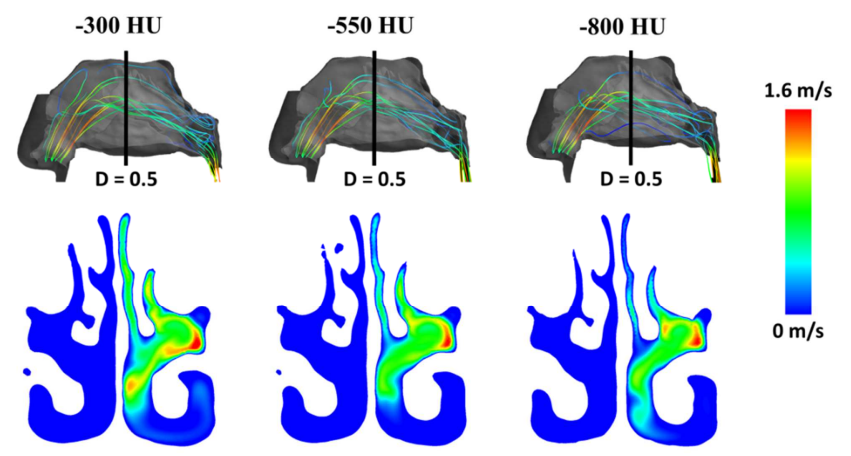

Figure 5. Model to the top shows inspiratory streamlines. The air velocity colormap at coronal section $D=0.5$ (main air stream flow) is shown at the bottom. The right nostril was assumed to be blocked to reproduce rhinomanometry measurements of unilateral resistance in the left cavity.

Subsequent study by Kawarai et al. [75] validates that indisputably, some anatomic variables such as airspace and cross-sectional area, as well as some computational fluid dynamics variables like pressure drop and airflow resistance, are strongly dependent on the segmentation threshold. However, variables such as surface area and intranasal flow distribution have been discovered to be less sensitive to the choice of segmentation threshold used during CFD.

\section{Central and Lower Airway Obstruction}

\subsection{CFD in Reduced Lower Airway Models}

Airflow along the human airways can be impeded at any region in the respiratory system. For instance, airflow obstructions occurring within the trachea and main-stem bronchi are referred to as central airway obstructions; a condition that can lead to lung diseases [76]. In the lower airway which typically involve the bronchioles and the alveoli, these condition could be malignant (e.g. Bronchogenic) or Non-malignant (e.g. Tuberculosis) and they are significant cause of morbidity and mortality across the 
globe [10, 77-79]. Over the years, CFD studies of central and lower airway have gained extensive research attention both experimentally and numerically as medical practitioners seek to understand the underlying mechanics of diseases in the human airway tract. Of both central and lower airways, conditions pertaining to the lower airways are more difficult to diagnose $[80,81]$. Construction of accurate geometry of the entire airway generation is also a complex work because obtaining scan based models is presently limited to the mouth cavity and a few lower airway generations. This is due to limited resolution of the scanned images for lower generation of the human airways [82].

Most studies of the lower airway involve computational approach by employing the most used Weibel's and Horsfield's models [83-84]. Consequently, most studies in this area have often considered computational technique with reduced branches of airway geometries [85-88]. To validate the use of airway models with a reduced number of airway branches, Bora et al. [82] developed multi-scale three 3-D airway models for central and peripheral airways with different numbers of airway branches and performed airflow simulation in the complex branches as shown in Figure 6 . They realized that to base investigation of airflow obstruction in the lower airways on complex models depicting the entire airway generation, it would be necessary to develop a multiscale model that describes cellular responses in addition to the global airflow distribution, which is invariably time consuming. However, their work, with other similar system of models, provided a starting framework to develop such multi-scale models [89].

A CFD approach in the investigation of the lower airways will typically involve some assumptions, boundary conditions and governing equations that have been established as simple and feasible standards over time in specifying the velocity inlet and outlet (see $[81,90,91,52$, 92-94]. Generally speaking, studies of the lower airways typically apply a laminar profile at the trachea, which is the point of delineation between the extra-thoracic airway (ETA) and the lower airways [95-97]. However, the effects of upper airway truncation on downstream airflow during simulations of the lower airways have been evaluated in recent studies, and none has been able to establish that modeling the lower airways without inclusion of the upper airway (nasal airspace) has substantial limitation on CFD results of downstream airflow in the lower airways [98-102]. Conversely, Jamasp et al. [103] compared flow patterns in two different ninegeneration models of the lower airways. The first included the extra-thoracic airways to constitute the upper airway flow and the second was the popular Weibel's and Horsfield's models. They concluded that models of the lower airways that ignore the effect of upper airway turbulent flow in their simulation may be misleading, and not suitably rendering a holistic insight into the airflow behavior through the human respiratory system. Their research may be considered as an improvement over the popularly used RANS turbulent models (the $\mathrm{k}-\varepsilon$ or $\mathrm{k}-\omega$ models) and LES technique used in most studies for simulation of airflow in the lower airways.
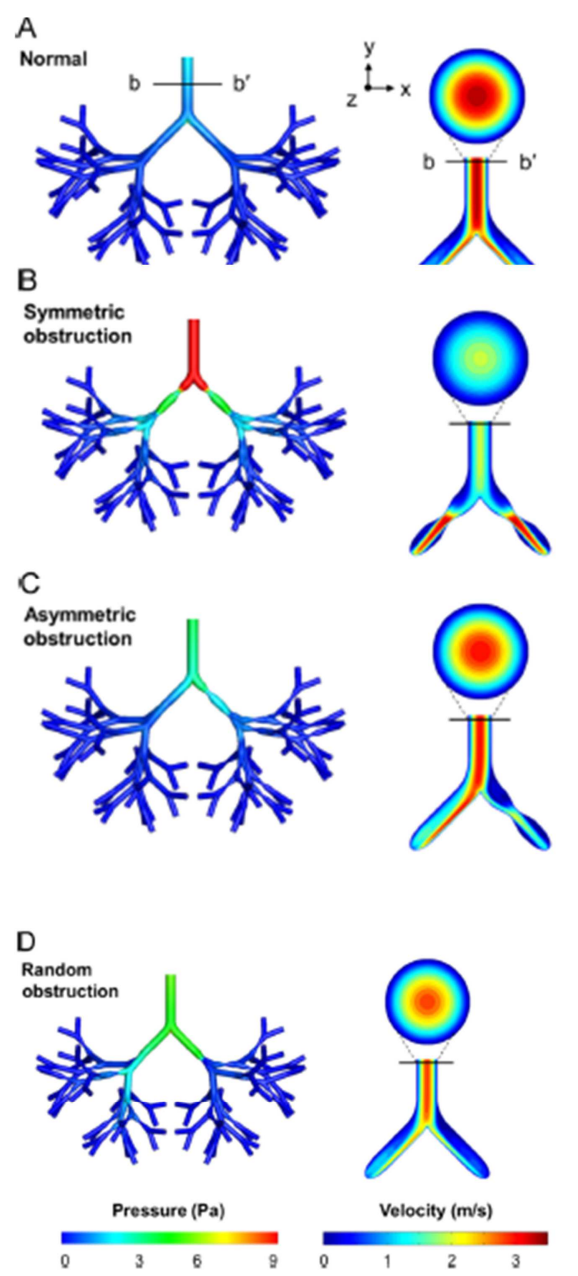

Figure 6. Steady flow computational models and simulation of the bronchi during inspiration in multi-scale models, where $(A)$ shows the normal airway, (B) symmetric obstruction (C) asymmetric obstruction and (D) random obstruction.

\subsection{CFD in Models of Different Age Groups}

It is important to consider patient specific models when investigating respiratory airflow obstruction. A realistic geometry reconstructed from scaled images of the airway structure provides a more accurate prediction into the airflow patterns along the respiratory tract. Logically, the human organs are different in size and properties for infants, children and adults. It is therefore important to compare simulations in different age groups. Consequently, Lee et al. [104] compared the effects of physiological features on airflow patterns and particle deposition in a child and adult models of the upper respiratory tract (URT). The models included the mouth cavity, pharynx, larynx, trachea and bronchial $(\mathrm{G} 1-\mathrm{G} 3)$ airways, that was established on the geometry of anatomical data of a three year old child and idealized adult model. The authors observed that at varying inspiration rates, distinctive airflow velocity streamlines were developed in both models despite the similarities in the airflow pattern.

Accordingly, Endalew [30] investigated the inspiratory and expiratory airflow characteristics in tracheobronchial airway models of an infant, a child and an adult. The idealized models 
with different geometries consist of airway generation six to nine (G6-G9). [31] reported that respiratory airflow dynamics in the three age groups was different; the airflow characteristics (velocity, pressure, and wall shear stress) decrease with age during inspiration and expiration; and there is variation of airflow pattern among the three age groups and between the two phases of respiration. Simulations for inspiration (a) and expiration (b) at the first bifurcation in infant, child, and adult are illustrated in figure 7.

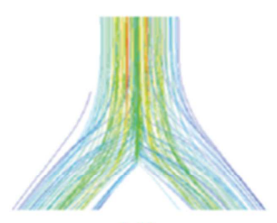

(A)

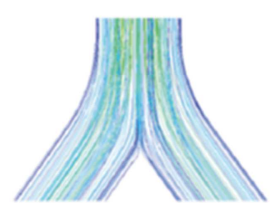

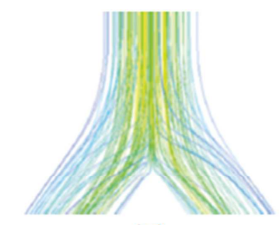

(B)

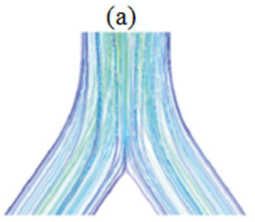

(b)

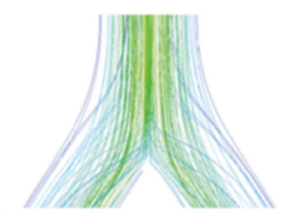

(C)

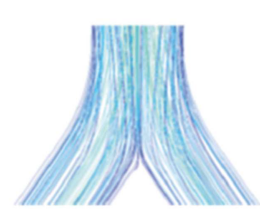

planning and outcomes for both patients and healthcare givers. The current CFD techniques offer comprehensive flow parameters that have greatly boost the investigation and evaluation of medical challenges, thereby providing researchers with robust data for diagnosis and treatment [108]. Interestingly, the application of CFD has generally reduced the use of animals and humans in direct testing; minimizing the risk to life and enhancing bioethics. More so, the ability to isolate specific phenomena for study irrespective of the location in the system, gives CFD a stable control over physical processes [109-110].

\subsection{Disadvantages}

Despite the current benefits of CFD, there are some limitations that can be improved on. The accuracy of CFD depends greatly on the initial boundary conditions of the numerical model. Consequently, individual outcomes can only be as accurate as the real-life physical model [111]. There are still limitations in accurately predicting flow behavior in vortex dominated, complex separated, and unsteady flows [1]. Thus, CFD results must be thoroughly evaluated before being generalized to prevent misinformation especially in pre-surgical cases. More so, it is apparent that CFD simulations require time and high performance computers and as such, is currently unsuitable for use in individual patient [112]. CFD simulations now touch 109 elements, implying that even with iterative solvers, a single step of simulation will require up to 100 gigabytes of storage and a computing time on the order of $106 \mathrm{~s}$, which is relatively costly and time consuming [37]. However, it is conceivable that technology would be available to optimize CFD simulation processes, making simulation results possible under the shortest possible time.

\subsection{Prospects}

The accuracy of clinical diagnosis is currently increasing through banks of data generated from patient's respiratory system utilizing machine learning. Mekov et al. [113] has predicted that the performance of CFD in respiratory diseases, as with other areas of its application, will be advanced by deep machine learning (ML) [114-115]. The improvement will include simulation speed, accuracy of results, and the user-friendliness of the CFD software [116-118]. Precisely, computer programmer are currently using machine learning to develop automatic classifiers information from different networks which produce signals that are going to be used for performing certain tasks. They will be used as pattern recognition to optimize and detect airflow obstruction in patients [119-122]. Ultimately, individualized CFD studies may be a viable diagnostic tool in the nearest future with the integration of deep learning to derive patient's specific data.

\section{Conclusions}

Herein the present study, an assessment of published literature on the modeling of upper and lower airway was possibility will definitely improve the efficacy of surgical 
made. The aim was to discuss different recent developments in the application of computational fluid dynamics (CFD), specifically on the investigation of airflow obstruction in the respiratory system. Insights into the limitations, advantages and the prospects of CFD focusing on diagnosis of human airway obstruction and diseases were discussed. The key conclusions from the review are: first, the reconstruction of $3 \mathrm{D}$ models of the nasal cavity is complex; therefore, the accuracy of nasal airflow simulation depends on the accuracy of the geometry reconstructed from MRI or CT scan. Second, the Weibel's model assumes steady airflow at the inlet in the thoracic model during inspiratory simulation; in the extrathoracic airway (ETA), the converse is true. The ETA reveals that most times, the airflow is in fact turbulent at the inlet. Third, segmentation threshold strongly impacts anatomic variable such as airspace area and volume, as well as CFD variables such as pressure drop and airflow resistance. Hence, the radio-density threshold for segmentation of the nasal airway needs more attention in CFD studies. Fourth, comparison of airflow simulation in models of infant, a child, and adult under the same respiratory condition shows similar flow patterns but obviously different airflow behaviors. Fifth, modeling the entire lower airway generation is complex, time consuming and would require developing a multi-scale model that describes cellular responses in addition to the global airflow distribution. Consequently, researches have been limited to predicting airflow in the lungs through simulations of airflow in few generations. It is indisputable that CFD has improved clinical assessment of complex respiratory challenges that are difficult to investigate through experiments. It is expected that future CFD studies, coupled with machine learning, will facilitate improved human respiratory health.

\section{Conflicts of Interest}

All the authors do not have any possible conflicts of interest about the publication of this paper.

\section{References}

[1] Witherden and Jameson, (2017) Future Directions of Computational Fluid Dynamics American Institute of Aeronautics and Astronautics. http://aerocomlab.stanford.edu/Papers/aiaa_cfd_future_2017.p df.

[2] Jeny Emmanuel (2020). Application of Computational Fluid Dynamics To Assess The Aerodynamics Of Upper Airway In The Field Of Orthodontics - A Review. European Journal of Molecular \& Clinical Medicine. ISSN 2515-8260 Volume 07, Issue $\quad 03,2020$. https://ejmcm.com/article 5972 48926d2a6f09c16f0f95ef398 063eaad.pdf.

[3] Wong, Chong Y., Solnordal, Christopher B., and Jie Wu. "CFD Modeling and Experimental Observations of Changing Surface Profiles Caused by Solid-Particle Erosion." SPE Prod \& Oper 29 (2014): 61-74. doi: https://doi.org/10.2118/157983-PA.
[4] Kiraly AP, Higgins WE, McLennan G, Hoffman EA, Reinhardt JM. Three-dimensional human airway segmentation methods for clinical virtual bronchoscopy. Acad Radiol. 2002; 9 (10): 1153-68. [PubMed] [Google Scholar].

[5] Muhsun, S. S., Saleh, M. S. \& Qassim, A. R. Physical and CFD Simulated Models to Analyze the Contaminant Transport through Porous Media under Hydraulic Structures. KSCE $J$ $\begin{array}{llll}\text { CivEng } & 24, & 3674-3691 & \text { (2020). }\end{array}$ https://doi.org/10.1007/s12205-020-1767-6.

[6] Chen, Qikun \& Peng, Shanbi \& Liu, Enbin. (2020). The Role of Computational Fluid Dynamics Tools on Investigation of pathogen transmission: Prevention and Control. Science of $\begin{array}{lll}\text { The Total Environment. 746. } & 142090 .\end{array}$ 10.1016/j.scitotenv.2020.142090.

[7] Khandve, Pravin \& Shelke, R. (2012). Application of CFD in Environment Engineering. 6. https://www.researchgate.net/publication/292695531_Applica tion_of_CFD_in_Environment_Engineering.

[8] Ana Fernández Tena, Pere Casan Clarà (2015) Use of Computational Fluid Dynamics in Respiratory Medicine. Vol. 51. Issue 6. pages 293-298. DOI: 10.1016/j.arbr.2015.03.00.

[9] Woldeamanuel, G. G., Mingude, A. B. \& Geta, T. G. Prevalence of chronic obstructive pulmonary disease (COPD) and its associated factors among adults in Abeshge District, Ethiopia: a cross sectional study. BMC Pulm Med 19, 181 (2019). https://doi.org/10.1186/s12890-019-0946-z D'Urzo, A. D., Tamari, I., Bouchard, J., Jhirad, R., \&Jugovic, P. (2011). Limitations of a spirometry interpretation algorithm. Canadian family physician Medecin de famille canadien, 57 (10), 1153-1156.

[10] World Health Organization, World Health Statistics 2008, http://www.who.int/whosis/whostat/2008/en/,2008.

[11] Gamboa F, Fernandez G, Padilla E, Manterola JM, Lonca J, Cardona PJ, Matas L, Ausina V. Comparative evaluation of initial and new versions of the Gen-Probe Amplified Mycobacterium Tuberculosis Direct Test for direct detection of Mycobacterium tuberculosis in respiratory and nonrespiratory specimens. J Clin Microbiol. 1998 Mar; 36 (3): 684-9. doi: 10.1128/JCM.36.3.684-689.1998. PMID: 9508296; PMCID: PMC104609.

[12] Heder de Vries, Annemijn Jonkman, Zhong-Hua Shi, Angélique Spoelstra-de Man, Leo Heunks Ann Transl Med. 2018 Oct; 6 (19): 387. doi: 10.21037/atm.2018.05.53. PMCID: PMC621236.

[13] K. P. Van de Woestijne, H. Franken, M. Cauberghs, F. J. Làndsér, J. Clément (1981) A modification of the forced oscillation technique. Pages 655-660, ISBN 9780080268231, https://doi.org/10.1016/B978-0-08-026823-1.50083-1.

[14] J. V. Rundo (2014) Polysomnography; Technique. Encyclopedia of the Neurological Sciences (Second Edition). Academic Press, Pages 930-935, ISBN 9780123851581, https://doi.org/10.1016/B978-0-12-385157-4.00537-6.

[15] Joseph Feher (2017) Lung Volumes and Airway Resistance. Quantitative Human Physiology (Second Edition), Academic Press, 2017, Pages 633-641, ISBN 9780128008836, https://doi.org/10.1016/B978-0-12-800883-6.00061-6.

[16] Joe L. Mauderly (1990) Measurement of Respiration and Respiratory Responses During Inhalation Exposures. Journal of the American college of toxicology Volume 9, Number 4, 1990 Mary Ann Liebert, Inc., Publishers. 
[17] J A. Richards (Consultant Pulmonologist) (2006) Office spirometry - indications and limitations, South African Family Practice, 48: 2, 48-51, $\quad$ DOI: 10.1080/20786204.2006.10873340.:

https://doi.org/10.1080/20786204.2006.10873340.

[18] H. Normand, F. Normand, X. Le Coutour, M-A. Metges, A. Mouadil (2007). Clinical evaluation of a screen pneumotachograph as an in-line filter, European Respiratory Journal Aug 2007, 30 (2) 358-363; DOI: $10.1183 / 09031936.06 .00148105$.

[19] E. Oostveen. D. MacLeod, H. Lorino, R. Farré, Z. Hantos, K. Desager, and F. Marchal (2013). The forced oscillation technique in clinical practice: methodology, recommendations and future developments; European Respiratory Society. DOI: https://doi.org/10.1183/09031936.03.00089403. PubMed: 14680096.

[20] Dorottya Czovek, Claire Shackleton, Kate Taylor, Zoltan Gingl, Zoltan Hantos, Peter Sly (2015) Limitations of forced spirometry in the detection of bronchodilator response in asthmatic children; European Respiratory Journal. Sep 2015, 46 (suppl 59) PA1258; DOI: 10.1183/13993003.congress2015.PA1258.

[21] Riazuddin, V. N.; Zubair, M.; Abdullah, M. Z.; Ismail, R.; Shuaib, I. L.; Hamid, S. A.; Ahmad, K. A. Numerical study of inspiratory and expiratory flow in a human nasal cavity. $J$. Med Biol. Eng. 2011, 31, 201-206.

[22] Yijuan Di, MinruiFei, Xin Sun, and T. C. Yang (2010) Modeling of the Human Bronchial Tree and Simulation of Internal Airflow. Springer-Verlag Berlin Heidelberg; K. Li et al. (Eds.): LSMS/ICSEE 2010, Part I, LNCS 6328, pp. 456$465,2010$.

[23] Fernández Tena $\mathrm{A}$, Casan Clarà $\mathrm{P}$. Use of computational fluid dynamics in respiratory medicine. Arch Bronconeumol. 2015 Jun; 51 (6): 293-8. English, Spanish. doi: 10.1016/j.arbres.2014.09.005. Epub 2015 Jan 22. PMID: 25618456.

[24] SCONA (2018) Society for Computational Fluid Dynamics of the Nose and Airway. Confrence Program London, UK. www.SCONA_2018_Detailed_Program_FINAL4.pdf.

[25] Heenan, A.; Matida, E.; Pollard, A.; Finlay, W. Experimental measurements and computational modeling of the flow field in an idealized human oropharynx. Exp. Fluids 2003, 35, 7084.

[26] Weinhold I, Mlynski G. Numerical simulation of airflow in the human nose. Eur Arch Otorhinolaryngol 2004; 261: 452455.

[27] Zhao, K., Malhotra, P., Rosen, D., Dalton, P., \&Pribitkin, E. A (2014). Computational fluid dynamics as surgical planning tool: a pilot study on middle turbinate resection. Anatomical record (Hoboken, N. J.: 2007), 297 (11), 2187-2195. https://doi.org/10.1002/ar.23033.

[28] Faizal WM, Ghazali NNN, Khor CY, et al. Computational fluid dynamics modelling of human upper airway: A review. Comput. Methods Programs Biomed. 2020; 196: 105627. doi: 10.1016/j.cmpb.2020.105627.

[29] Ezzie, M. E., Parsons, J. P., Mastronarde, J. G.: Sleep and obstructive 1 ung diseases. Sleep Med. Clin. 3 (4), 505-515 (2008).
[30] Endalew Getnet T sega (2018) Computational Fluid Dynamics Modeling of Respiratory Airflow in Tracheobronchial Airways of Infant, Child, and Adult; Hindawi Computational and Mathematical Methods in Medicine Volume 2018, Article ID 9603451, 9 pages https://doi.org/10.1155/2018/9603451.

[31] Lanlan Zhang, Lixiu He, Jin Gong, Chuntao Liu, "Risk Factors Associated with Irreversible Airway Obstruction in Asthma: A Systematic Review and Meta-Analysis", BioMed Research International, vol. 2016, Article ID 9868704, 10 pages, 2016. https://doi.org/10.1155/2016/9868704.

[32] S. Kumar and R. Salib (2006), Upper airway obstruction is a serious and potentially life-threatening condition and as such requires prompt assessment and management. In Encyclopedia of Respiratory Medicine.

[33] Casey, K. P., Borojeni, A. A. T., Koenig, L. J., Rhee, J. S., and Garcia, G. J. M. (2017). Correlation between Subjective Nasal Patency and Intranasal Airflow Distribution. Correlation between subjective nasal patency and intranasal airflow distribution. Otolaryngol Head Neck Surg. 156: 741-750.

[34] Gaberino C., Rhee, J. S., Garcia, G. J. (2018). Estimates of nasal airflow at the nasal cycle mid-point improve the correlation between objective and subjective measures of nasal patency. Respir Physiol Neurobiol. 238: 23-32.

[35] Cherobin GB, Voegels RL, Gebrim EMMS, Garcia GJM (2018) Sensitivity of nasal airflow variables computed via computational fluid dynamics to the computed tomography segmentation threshold. PLoS ONE 13 (11): e0207178. https://doi.org/10.1371/journal. pone.0207178.

[36] Leong, S \& Chen, X \& Lee, Hp \& Wang, DY. (2010). A review of the implications of computational fluid dynamic studies on nasal airflow and physiology. Rhinology. 48. 13945. 10.4193/Rhin09.133.

[37] Last, Carsten \& Winkelbach, Simon \& Wahl, Friedrich \& Eichhorn, Klaus \& Bootz, Friedrich. (2010). A Model-Based Approach to the Segmentation of Nasal Cavity and Paranasal Sinus Boundaries. 6376. 333-342. 10.1007/978-3-642-15986-2 34.

[38] Bui NL, Ong SH, Foong KW. Automatic segmentation of the nasal cavity and paranasal sinuses from cone-beam CT images. Int J Comput Assist Radiol Surg. 2015 Aug; 10 (8): 1269-77. doi: 10.1007/s11548-014-1134-5. Epub 2014 Dec 12. PMID: 25503593.

[39] Girardin, M., Bilgen, E., Arbour, P.: Experimental study of velocity fields in a human nasal fossa by laser anemometry. Ann. Otol. Rhinol. Laryngol. 92 (3 pt 1), 231-236 (1983).

[40] Zhao, Y., Lieber, B. B.: Steady inspiratory flow in a model symmetric bifurcation. J. Biomech. Eng. 116 (4), 488-496 (1994).

[41] Corcoran, T. E., Chigier, N.: Characterization of the laryngeal jet using phase doppler interferometry. J. Aerosol. Med. 13 (2), 125-137 (2002).

[42] Kim, S. K., Chung, S. K.: An investigation on airflow in disordered nasal cavity and its corrected models by tomographic PIV. Meas. Sci. Technol. 15 (6), 1090-1096 (2004).

[43] Ying Wang, Yingxi Liu, Xiuzhen Sun, Shen Yu, Fei Gao (2009) Numerical analysis of respiratory flow patterns within human upper airway. The Chinese Society of Theoretical and Applied Mechanics and Springer-Verlag GmbH 2009; Acta Mech Sin (2009) 25: 737-746 DOI 10.1007/s10409-0090283-1. 
[44] Stapleton, K. W., Guentsch, E., Hoskinson, M. K., et al.: On the suitability of $\kappa-\varepsilon$ turbulence modeling for aerosol deposition in the mouth and throat: a comparison with experiment. J. Aerosol. Sci. 31 (6), 739-749 (2012).

[45] Jin, H. H., Fan, J. R., Zeng, M. J., et al.: Large eddy simulation of inhaled particle deposition within the human upper respiratory tract. J. Aerosol Sci. 38 (3), 257-268 (2007).

[46] Subramaniam, R. P., Richardson, R. B., Morgan, K. T., et al.: Computational fluid dynamics simulations of inspiratory airflow in the human nose and nasopharynx. Inhal. Toxicol. 10 (5), 473- 502 (1998).

[47] Ma, B., Lutchen, K.: CFD simulation of aerosol deposition in an anatomically based human large-medium airway model. Ann. Biomed. Eng. 37 (2), 271-285 (2009).

[48] Yu, S., Liu, Y. X., Sun, X. Z., et al.: Influence of nasal structure on the distribution of airflow in nasal cavity. Rhinology 46 (2), 137- 143 (2008).

[49] Renotte, C., Bouffioux, V., Wilquem, F.: Numerical 3D analysis of oscillatory flow in the time-varying laryngeal channel. J. Biomech. 33 (12), 1637-1644 (2002).

[50] Doorly, D. J., Taylor, D. J., Schroter, R. C.: Mechanics of airflow in the human nasal airways. Respir. Physiol. Neurobiol. 163 (1-3), 100-110 (2008).

[51] Calay, R. K., Kurujareon, J., Holdø, A. E.: Numerical simulation of respiratory flow patterns within human lung. Respir. Physiol. Neurobiol. 130 (2), 201-221 (2002).

[52] Lin, C. L., Tawhai, M. H., McLennan, G., et al.: Characteristics of the turbulent laryngeal jet and its effect on airflow in the human intra-thoracic airways. Respir. Physiol. Neurobiol. 157 (2-3), 295-309 (2007).

[53] Zhang, Z., Kleinstreuer, C.: Transient airflow structures and particle transport in a sequentially branching lung airway model. Phys. Fluids 14 (2), 862-880 (2002).

[54] Xu, C., Sin, S. H., McDonough, J. M., et al.: Computational fluid dynamics modeling of the upper airway of children with obstructive sleep apnea syndrome in steady flow. J. Biomech. 39 (11), 2043-2054 (2006).

[55] Sun, X. Z., Yu, C., Wang, Y., et al.: Numerical simulation of soft palate movement and airflow in human upper airway by fluid-structure interaction method. Acta. Mech. Sin. 23 (4), 359-367 (2007).

[56] Freitas RK, Schroder W: Numerical investigation of the threedimensional flow in a human lung model. J Biomech 2008, 41 (11): $2446-2457$

[57] Banno, K., Kryger, M. H.: Sleep apnea: Clinical investigations in humans. Sleep Med. 8 (4), 400-426 (2007).

[58] Jeong, S. J., Kim, W. S., Sung, S. J.: Numerical investigation on the flow characteristics and aerodynamic force of the upper airway of patient with obstructive sleep apnea using computational fluid dynamics. Med. Eng. Phys. 29 (6), 637-651 (2007).

[59] Chouly, F., A. Van Hirtum, P. Y. Lagree, X. Pelorson, and Y. Payan. 2008. Numerical and experimental study of expiratory flow in the case of major upper airway obstructions with fluidstructure interaction. J. Fluids Struct. 24: 250-269.

[60] Pirnar, J., L. Dolenc-Groselj, I. Fajdiga, and I. Zun. 2015. Computational fluid-structure interaction simulation of airflow in the human upper airway. J. Biomech. 48: 3685-3691.

[61] Subramaniam, D. R., G. Mylavarapu, R. J. Fleck, R. S. Amin, S. R. Shott, and E. J. Gutmark. 2017. Effect of airflow and material models on tissue displacement for surgical planning of pharyngeal airways in pediatric down syndrome patients. $J$. Mech. Behav. Biomed. Mater. 71: 122-135.

[62] Trung B. Le, Masoud G. Moghaddam, B. Tucker Woodson \& Guilherme J. M. Garcia (2019). Airflow limitation in a collapsible model of the human pharynx: physical mechanisms studied with fluid-structure interaction simulations and experiments. Physiol Rep, 7 (10), 2019, e14099, https://doi.org/10.14814/phy2.14099.

[63] Chang, K. K., K. B. Kim, M. W. McQuilling, and R. Movahed. 2018. Fluid structure interaction simulations of the upper airway in obstructive sleep apnea patients before and after maxillomandibular advancement surgery. Am. J. Orthod. Dentofac. 153: 895-904.

[64] Liu, Y., J. Mitchell, Y. Chen, W. Yim, W. Chu, and R. C. Wang. 2018. Study of the upper airway of obstructive sleep apnea patient using fluid structure interaction. Respir. Physiol. Neurobiol. 249: 54-61.

[65] Chouly Zhao, M., T. Barber, P. A. Cistulli, K. Sutherland, and G. Rosengarten. 2013. Simulation of upper airway occlusion without and with mandibular advancement in obstructive sleep apnea using fluid-structure interaction. J. Biomech. 46: 25862592.

[66] Dawson, S. V., and E. A. Elliott. 1977. Wave-speed limitation on expiratory flow-a unifying concept. J. Appl. Physiol. Respir. Environ. Exerc. Physiol. 43: 498-515.

[67] Wellman, A., P. R. Genta, R. L. Owens, B. A. Edwards, S. A. Sands, S. H. Loring, et al. 2014. Test of the Starling resistor model in the human upper airway during sleep. J. Appl. Physiol. 117: 1478-1485.

[68] Genta, P. R., S. A. Sands, J. P. Butler, S. H. Loring, E. S. Katz, B. G. Demko, et al. 2017. Airflow shape is associated with the pharyngeal structure causing OSA. Chest 152: 537-546.

[69] Chaoqun Fang, Xiu Ying Wang, David Dagan Feng, Airway Segmentation for Low-Contrast CT Images from Combined PET/CT Scanners Based on Airway Modeling and Seed Prediction, IFAC Proceedings Volumes, Volume 42, Issue 12, 2009, Pages 198-203, ISSN 1474-6670, ISBN 9783902661494, https://doi.org/10.3182/20090812-3-DK2006.0051 .

[70] Artaechevarria, Xabier \& Pérez-Martín, D \& Ceresa, Mario \& de Biurrun, Gabriel \& Blanco, D \& Montuenga, L \& Ginneken, B \& Ortiz-de-Solorzano, Carlos \& Muñoz-Barrutia, Arrate. (2009). Airway segmentation and analysis for the study of mouse models of lung disease using micro-CT. Physics in medicine and biology. 54. 7009-24. 10.1088/00319155/54/22/017.

[71] Gil D, Sanchez C, Borras A, Diez-Ferrer M, Rosell A (2019) Segmentation of distal airways using structural analysis. $\begin{array}{lllll}\text { PLOS } & \text { ONE } & 14 & \text { (12): } & \text { e226006. }\end{array}$ https://doi.org/10.1371/journal.pone.0226006.

[72] Reynisson PJ, Scali M, Smistad E, Hofstad EF, Leira HO, Lindseth F, et al. (2015) Airway Segmentation and Centerline Extraction from Thoracic CT - Comparison of a New Method to State of the Art Commercialized Methods. PLoS ONE 10 (12): e0144282. https://doi.org/10.1371/journal.pone.0144282. 
[73] Nakano H, Mishima K, Ueda Y, Matsushita A, Suga H, Miyawaki Y, et al. A new method for determining the optimal CT threshold for extracting the upper airway. Dentomaxillofacial Radiol. 2013; 42 (3): 26397438 10.1259/dmfr/26397438. [PMC free article] [PubMed] [Google Scholar].

[74] Quadrio, M., Pipolo, C., Corti, S. et al. Effects of CT resolution and radiodensity threshold on the CFD evaluation of nasal airflow. Med Biol Eng Comput 54, 411-419 (2016). https://doi.org/10.1007/s11517-015-1325-4.

[75] Kawarai Y, Fukushima K, Ogawa T, Nishizaki K, Gunduz M, Fujimoto M, et al. Volume quantification of healthy paranasal cavity by three-dimensional CT imaging. Acta Otolaryngol Suppl. 1999; 540: 45-9. PMID: 10445079.

[76] Weissheimer A, Menezes LM, Sameshima GT, Enciso R, Pham J, Grauer D. Imaging software accuracy for 3dimensional analysis of the upper airway. Am J Orthod Dentofacial Orthop. 2012; 142 (6): 801-13. https://doi.org/10.1016/j.ajodo.2012.07.015 PMID: 23195366.

[77] Alsufyani NA, Flores-Mir C, Major PW. Three-dimensional segmentation of the upper airway using cone beam CT: a systematic review. Dentomaxill of acRadiol. 2012; 41 (4): 276-84. https://doi.org/10.1259/dmfr/79433138 PMID: 22517995.

[78] David Zwicker et al (2018). Validated reconstructions of geometries of nasal cavities from CT scans. Biomed. Phys. Eng. Express 4 045022. https://doi.org/10.1088/20571976/aac6af.

[79] Christer Janson, Guy Marks, Sonia Buist, Louisa Gnatiuc, Thorarinn Gislason, Mary Ann McBurnie, Rune Nielsen, Michael Studnicka, Brett Toelle, Bryndis Benediktsdottir, Peter Burney (2013). The impact of COPD on health status: findings from the BOLD study. European Respiratory Journal 2013 42: 1472-1483; DOI: 10.1183/09031936.00153712.

[80] Armin Ernst, David Feller-Kopman, Heinrich D. Becker, and Atul C. Mehta (2004) Central Airway Obstruction, American Journal of Respiratory and Critical Care Medicine. Volume 169, Issue 12. https://doi.org/10.1164/rccm.200210-1181SO.

[81] Hui Chen, Jie Zhang, Xiaojian Qiu, Juan Wang, Yinghua Pei, Yuling Wang, Ting Wang. (2020) Choice of bronchoscopic intervention working channel for benign central airway stenosis. Internal and Emergency Medicine 40. Online publication date: 23 -Oct-2020. Crossref.

[82] Bora Sul, Anders Wallqvist, Michael J. Morris, Jaques Reifman, Vineet Rakesh, (2014). A computational study of the respiratory airflow characteristics in normal and obstructed human airways. Computers in Biology and Medicine, Volume 52, Pages 130-143, ISSN 0010-4825, https://doi.org/10.1016/j.compbiomed.2014.06.008

[83] D. B. Coultas, D. Mapel, R. Gagnon, E. Lydick, The health impact of undiagnosed airflow obstruction in a national sample of United States adults, Am. J. Respir. Crit. Care Med. 164 (2001) 372-377.

[84] Kolanjiyil, A. V. and Kleinstreuer, C. (2017). Computational analysis of aerosol dynamics in a human whole-lung airway model. J. Aerosol Sci. 114: 301-316.

[85] E. R. Weibel. Morphometry of the human lung: the state of the art after two decades Bull. Eur. Physiopathol. Respir., 15 (1979), pp. 999-1013 View Record in ScopusGoogle Scholar.
[86] K. Horsfield, G. Dart, D. E. Olson, G. F. Filley, G. CummingModels of the human bronchial tree J. Appl. Physiol., 31 (1971), pp. 207-217 CrossRefView Record in ScopusGoogle Scholar.

[87] Z. Zhang, C. Kleinstreuer, C. S. Kim Airflow and nanoparticle deposition in a 16-generation tracheobronchial airway model. Ann. Biomed. Eng., 36 (2008), pp. 2095-2110 CrossRefView Record in ScopusGoogle Scholar.

[88] N. Nowak, P. P. Kakade, A. V. Annapragada Computational fluid dynamics simulation of airflow and aerosol deposition in human lungs. Ann. Biomed. Eng., 31 (2003), pp. 374-390 View Record in ScopusGoogle Scholar.

[89] Brouns M, Jayaraju ST, Lacor C, De Mey J, Noppen M, Vincken W, Verbanck S: Tracheal stenosis: a flow dynamics study. J Appl Physiol 2007, 102 (3): 1178-1184.

[90] De Rochefort L, Vial L, Fodil R, Maître X, Louis B, Isabey D, Caillibotte G, Thiriet M, Bittoun J, Durand E, Sbirlea-Apiou G: In vitro validation of computational fluid dynamic simulation in human proximal airways with hyperpolarized3He magnetic resonance phasecontrastvelocimetry. J Appl Physiol 2012, 102 (5): 2012-2023.

[91] Justus KavitaMutuku, Wei-Hsin Chen (2018) Flow Characterization in Healthy Airways and Airways with Chronic Obstructive Pulmonary Disease (COPD) during Different Inhalation Conditions. Aerosol and Air Quality Research, 18: 2680-2694, 2018 ISSN: 1680-8584 print/ 20711409 doi: 10.4209 /aaqr.2018.06.0232.

[92] Luo HY, Liu Y: Modeling the bifurcating flow in a CTscanned human lung airway. J Biomech 2008, 41 (12): 26812688.

[93] Gemci T, Ponyavin V, Chen Y, Chen H, Collins R: Computational model of airflow in upper 17 generations of human respiratory tract. J Biomech 2008, 41 (9): 2047-2054.

[94] Lin C, Tawhai MH, McLennan G, Hoffman EA: Multiscale simulation of gas flow in subject specific models ofthe human lung. IEEE Eng Med Biol Mag 2009, 28 (3): 25-33.

[95] Tawhai MH, Hoffman EA, Lin CL: The lung physiome: merging imaging-based measures with predictive computational models. Wiley Interdiscip Rev SystBiol Med 2009, 1 (1): 61-72.

[96] Chen, X., Zhong, W., Sun, B., Jin, B. and Zhou, X. (2012). Study on gas/solid flow in an obstructed pulmonary airway with transient flow based on CFD-DPM approach. Powder Technol. 217: 252-260.

[97] Johnstone A, Uddin M, Pollard A, Heenan A, Finlay W. H., "The flow inside an idealised form of the human extra-thoracic airway," Experiments in Fluids, pp. 37 (5), 673-689, 2004.

[98] Ball, C. G., Uddin, M., \& Pollard, A., "High resolution turbulence modelling of airflow in an idealised human extra-thoracic airway," Computers \& Fluids, pp. 37 (8), 943-964, 2008a.

[99] Kleinstreuer, C., \& Zhang, Z., "Airflow and particle transport in the human respiratory system," Annual Review of Fluid Mechanics, pp. 42, 301-334, 2010.

[100] Jayaraju, S. T., Brouns, M., Lacor, C., Belkassem, B., \&Verbanck, S., "Large eddy and detached eddy simulations of fluid flow and particle deposition in a human mouth throat," Journal of Aerosol Science, pp. 39 (10), 862-875, 2008. 
[101] Mylavarapu, G., Murugappan, S., Mihaescu, M., Kalra, M., Khosla, S., \& Gutmark, E., "Validation of computational fluid dynamics methodology used for human upper airway flow simulations," Journal of biomechanics, pp. 42 (10), 1553$1559,2009$.

[102] Mihaescu, M., Khosla, S. M., Murugappan, S., \&Gutmark, E. J., "Unsteady laryngeal airflow simulations of the intra-glottal vortical structures," The Journal of the Acoustical Society of America, pp. 127 (1), 435-444, 2010.

[103] Jamasp Azarnoosh, Kidambi Sreenivas and Abdollah Arabshahi (2016) Computational fluid dynamics simulation of the airflow through the human respiratory tract. The International Conference on Computational Science. Elsevier volume 80, 2016, Pages 965-976. Doi: 10.1016/j.procs.2016.05.392.

[104] Lee, J. H., Na, Y., Kim, S. K., \& Chung, S. K., "Unsteady flow characteristics through a human nasal airway," Respiratory physiology \& neurobiology, pp. 172 (3), 136-146, 2010.

[105] Yasuo M, Kitaguchi Y, Tokoro Y, Kosaka M, Wada Y, Kinjo T, Ushiki A, Yamamoto H, Hanaoka M. Differences Between Central Airway Obstruction and Chronic Obstructive Pulmonary Disease Detected with the Forced Oscillation Technique. Int J Chron Obstruct Pulmon Dis. 2020; 15: 14251434https://doi.org/10.2147/COPD.S246126.

[106] Zhijian Liu, Angui Li, Xiaoxia Xu \& Ran Gao (2012) Computational Fluid Dynamics Simulation of Airflow Patterns and Particle Deposition Characteristics in Children Upper Respiratory Tracts, Engineering Applications of Computational Fluid Mechanics, 6: 4, 556-571, DOI: $10.1080 / 19942060.2012 .11015442$ To link to this article: https://doi.org/10.1080/19942060.2012.11015442.

[107] Lee BK. Computational fluid dynamics in cardiovascular disease. Korean Circ J 2011; 41 (8): 423-30.

[108] Iwasaki T, Sato H, Suga H, Minami A, Yamamoto Y, Takemoto Y, et al. Herbst appliance effects on pharyngeal airway ventilation evaluated using computational fluid dynamics. Angle Orthod. 2017; 87 (3): 397-403.

[109] Bockholt U, Mlynski G, Müller W, Voss G. Rhinosurgical therapy planning via endonasal airflow simulation. Comput Aided Surg 2000; 5: 175-179.

[110] Chen, W. H., Lee, K. H., Mutuku, J. K. and Hwang, C. J. (2018). Flow dynamics and PM2.5 deposition in healthy and asthmatic airways at different inhalation statuses. Aerosol Air Qual. Res. 18: 866-883.

[111] Patel, M. (Jan. 2013). "Computational Fluid Dynamics (CFD) Simulation BeneÕts Practical Applications." Retrieved from http://www.hitechcfd.com/cfd-

knowledgebase/cfdsimulationbeneÕts-practicalapplications.html.

[112] R. Orihara, R. Narasaki, Y. Yoshinaga, Y. Morioka and Y. Kokojima, "Approximation of Time-Consuming Simulation Based on Generative Adversarial Network," 2018 IEEE 42nd
Annual Computer Software and Applications Conference (COMPSAC), Tokyo, Japan, 2018, pp. 171-176, doi: 10.1109/COMPSAC.2018.10223.

[113] Mekov E, Miravitlles M, Petkov R. Artificial intelligence and machine learning in respiratory medicine. Expert Rev Respir Med. 2020 Jun; 14 (6): 559-564. doi: 10.1080/17476348.2020.1743181. Epub 2020 Mar 17. PMID: 32166988 .

[114]CR. Btech (2017). "Computational Fluid Dynamics And Applications." Retrieved from http://crbtech.in/CADCAMTraining/computational-Öuid-dynamics-applications/

[115]Red Metal Mining (2021) What Is Computational Fluid Dynamics (CFD)? Application \& Advantages: https://redmetal.co.za/engineering-services/computationalfluid-dynamics flow-simulation/.

[116] Sheikhtaheri A, Sadoughi F and Hashemi Dehaghi Z. Developing and using expert systems and neural networks in medicine: a review on benefits and challenges. J Med Syst. 2014; 38: 110 .

[117] Runchal A. K., Rao M. M. (2020) CFD of the Future: Year 2025 and Beyond. In: Runchal A. (eds) 50 Years of CFD in Engineering Sciences. Springer, Singapore. https://doi.org/10.1007/978-981-15-2670-1_22.

[118] KukrejaS A comprehensive study on the applications of artificial intelligence for the medical diagnosis and prognosis of asthma. [Cited 2019 Jul 16]. Available from SSRN: https://ssrn.com/abstract=3081746.

[119] Jorge L. M. Amaral, Agnaldo J. Lopes, Jose M. Jansen, Alvaro C. D. Faria, Pedro L. Melo, Machine learning algorithms and forced oscillation measurements applied to the automatic identification of chronic obstructive pulmonary disease, computer methods and programs in biomedicine. 105 (2012) 183-193. dio: 10.1016/cmpb.2011.09.009.

[120] Jorge L. M. Amaral, Agnaldo J. Lopes, Juliana Veiga, Alvaro C. D. Faria, and Pedro L. Melo. 2017. High-accuracy detection of airway obstruction in asthma using machine learning algorithms and forced oscillation measurements. Comput. Methods Prog. Biomed. 144, C (June 2017), 113-125. DOI: https://doi.org/10.1016/j.cmpb.2017.03.023.

[121]Elsa Angelini, Simon Dahan and Anand Shah (2019). Unravelling machine learning: insights in respiratory medicine; European Respiratory Journal. https://doi.org/10.1183/13993003.01216- 2019. vol. 54 no. 6.1399-3003.

[122] Alan Kaplan, Hui Cao, J. Mark FitzGerald, Nick Iannotti, Eric Yang, Janwillem W. H. Kocks, Konstantinos Kostikas, David Price, Helen K. Reddel, Ioanna T siligianni, Claus F. Vogelmeier, Pascal P. fister, Paul Mastoridis, Pharm D (2021). Artificial Intelligence/Machine Learning in Respiratory Medicine and Potential Role in Asthma and COPD Diagnosis. DOI: https://doi.org/10.1016/j.jaip.2021.02.014 The journal of allergy and clinical immunology. 